\title{
Enhancement on Sound Transmission Loss for Various Positioning of Inlet and Outlet Duct of the Muffler
}

\author{
Amit Kumar Gupta ${ }^{\mathrm{a}}$, Dr. Ashesh Tiwari ${ }^{\mathrm{b}}$ \\ ${ }^{a}$ Assistant Professor, Mechanical Engineering Department, IET-Devi Ahilya University, Indore, INDIA \\ ${ }^{b}$ Professor, Mechanical Engineering Department, IET-Devi Ahilya University, Indore, INDIA
}

\begin{abstract}
Muffler acts as noise reduction element on exhaust system. Noise from an automotive application is the major source of noise pollution. Here the transmission loss of central inlet and central outlet muffler of single expansion chamber has been compared and validated in three methods namely transfer matrix method, finite element analysis and an experimental method for this purpose an experimental setup has been built up which is based on two load method. Several researchers have worked in the area of noise attenuation on central inlet by changing the position of outlet as side outlet but no one emphasizes on offset of the central inlet and central outlet position. Thereafter the finite element analysis tool Ricardo wave 1-D and comsol multiphysics is used to evaluate transmission loss for various offset position of inlet and outlet duct of the muffler. The very purpose to improve the acoustic performance of central inlet with offset outlet pipe by measuring transmission loss of offset inlet with offset outlet with various positions by keeping same space. Finite element analysis shows that higher attenuation can be achieved by increasing offset distance of central inlet \& outlet outlet towards radial direction of the expansion chamber with the variation of $0.2 \mathrm{r}, 0.4 \mathrm{r}$ and $0.6 \mathrm{r}$. Here ' $r$ ' is radius of single expansion chamber. The result shows that high transmission loss can be achieved by increasing the offset radial distance of the inlet pipe and outlet pipe. Further higher attenuation can also be achieved in case of fixed the distance of offset inlet and outlet at $0.6 \mathrm{r}$ by rotating the offset outlet which is also offseted at $0.6 \mathrm{r}$ distance by $0^{\circ}$, $45^{\circ}, 90^{\circ}, 135^{\circ}$ and $180^{\circ}$. On ward rotation from remaining $180^{\circ}$ to $360^{\circ}$ the behavior of wave propagation will be same what has been reflected between $0^{\circ}$ to $180^{\circ}$. Transmission loss maximizes when the offset outlet is loacted at $90^{\circ}$. It clearly reveals that optimization can be achieved by using finite element analysis tool by using virtual protyping.
\end{abstract}

Index Terms: Transmission Loss (TL), Wave 1-D, Comsol, Inlet \& Outlet Duct.

(C) 2015 Published by MECS Publisher. Selection and/or peer review under responsibility of the Research Association of Modern Education and Computer Science.

\footnotetext{
* Corresponding author. Tel.: +919406653327

E-mail address: gupta.ak4@gmail.com
} 


\section{Introduction}

Exhaust noise pollution has become more challenging in present situation. The experimental approach of two-load method is commonly used to predict the transmission loss of an acoustic filters like muffler, resonator etc. Mufflers are essentially low-pass acoustical filters. Making use of electro acoustical analogies lumped inductance and capacitance of electrical wave filter are represented in mufflers by connecting pipes (ducts) and chambers (plenums) [1]. Here the finite element analysis is also used to show the comparative study of transmission loss of muffler. Muffler for an automobile is characterized by numerous parameters like insertion loss (IL), transmission loss (TL). The best used parameter is to evaluate the sound radiation characteristics of muffler is transmission loss (TL) [2]. This is the one of the most frequently used criteria of muffler performance because it can be determined very easily from the known physical parameters of the muffler. The numerical methods are allowing the analysis of all types of acoustic mufflers [3]. Hence it is essential to optimize the model by finite element analysis tool and has validate with experimental method. Validation of experimental setup it is necessary to test the results of model of which analytical, numerical results are known [4].The measured transmission losses are compared with finite element analysis simulation. It describes that the transmission losses can be determined reliably with the test rig setup [5]. The paper applies Hilbert-Huang Transform to process the fruit fly's wing vibration sound [6]. Many FEA tools are available to simulate the transmission loss characteristics of a muffler. In this paper, muffler is simulated by Finite Element Analysis tool like Ricardo Wave -1D \& Comsol which is used to predict muffler's transmission loss performances as well it is validated by experimental two load method [7]. To improve the acoustic performance author proposed central inlet with offset outlet and offset inlet with offset outlet with various possible positions by keeping same space constraints. It represents higher attenuation can achieved by increasing offset distance of central inlet \& outlet outlet towards end of the expansion chamber [8]. An accurate performance prediction by two load and by finite element analysis tool for muffler design could be greatly reduce the effort in fabricating and testing of different design iterations of muffler [9]. Noise from the automobile is generated by several sources such as the internal combustion engine, the brake system, the inlet and exhaust system and the flow around the body of the automobile [10]. Intake and exhaust system noise draws a huge contribution to the interior and exterior noise of cars [11]. A major factor in engine and vehicle emitted noise is the exhaust system. The greatest source of noise which disturbs people and creates impact on their environment comes from transport vehicles [12]. The huge increase in mobility achieved by technological development in the last century accompanied by high background noise levels, particularly due to road traffic, has become a feature of our society [13]. Noise contribution from various automotive systems shows that $32 \%$ of the overall noise produced by any engine is from the engine exhaust system. Generally, engines produce noise of 90 to $130 \mathrm{~dB}$ depending on the size and the type of the engine. Noise levels of more than $80 \mathrm{~dB}$ are injurious for human beings [14]. Many researcher has done the parametric studies to understand the effects of various parameters on cylindrically shaped muffler with different configurations. The acoustic behavior of reactive mufflers with central inlet and central outlet is investigated in detail by means of analytical approach for single chamber muffler [15]. Analytical procedure allows the determination of transmission loss of a muffler, and a general formula is derived for the given muffler with central outlet. The results are verified by transfer matrix method and finite element method. By adopting suitable dimensions of the muffler it is possible to improve acoustic performance of mufflers at low to mid frequencies. So the research regarding offsetting of inlet pipe and outlet pipe has not been done by any researcher. The research work regarding the measurement of transmission loss is missing for various radial offset positioning of inlet and outlet duct of the muffler. It represents higher attenuation can achieved by increasing offset distance of central inlet and outlet towards radial of the expansion chamber. Finite element analysis tool shows that high transmission loss can be achieved by increasing offset distance of central inlet and central outlet towards radial direction of the expansion chamber with the variation of $0.2 \mathrm{r}, 0.4 \mathrm{r}$ and $0.6 \mathrm{r}$. Here ' $r$ ' is radius of single expansion chamber. The high transmission loss can be achieved by increase the offset radial distance of the inlet pipe and outlet pipe. Further higher attenuation can also be achieved by fixing the offset distance of inlet and outlet at $0.6 \mathrm{r}$ distance and by rotating the offset outlet by $45^{\circ}, 90^{\circ}, 135^{\circ}, 180^{\circ}$. 
Transmission loss maximizes when the offset outlet is located at $90^{\circ}$. It clearly reveals that optimization can be achieved by using finite element analysis tool by using virtual prototyping. Hence the finite element analysis tool saves the substantial amount of time and resources.

\section{Modeling of Central Inlet and Central Outlet Muffler}

\subsection{Validation with Transfer Matrix Method}

A concentric-tube resonator consists of an external cylindrical tube and a perforated internal tube located coaxially. The two ends of the external cylindrical chamber are covered by circular flanges which are mounted on the internal tube. The external tube (expansion chamber) is $500 \mathrm{~mm}$ long and $130 \mathrm{~mm}$ diameter and the internal tube has a diameter of $35 \mathrm{~mm}$ shown in fig. 1 .

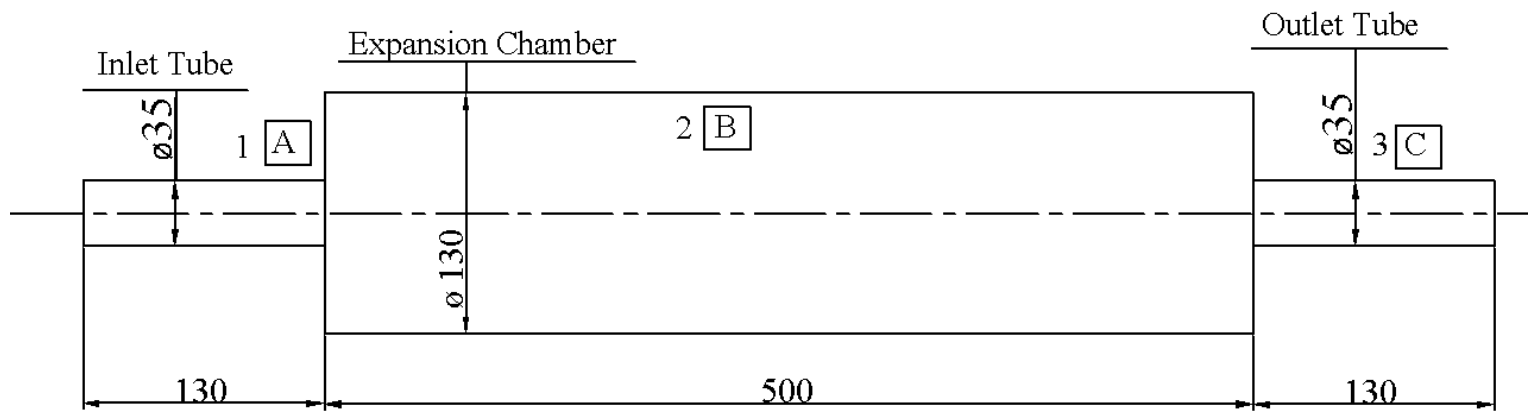

(All dimensions are in $\mathrm{mm}$ )

Fig.1. Single Expansion Chamber

The cascading property of four pole parameter approach, the transfer matrix for the muffler of Fig. 1 is given by [16],

$$
\left(\begin{array}{l}
\mathrm{P}_{1} \\
\mathrm{~V}_{1}
\end{array}\right)=\left[\begin{array}{ll}
\mathrm{T}_{11} & \mathrm{~T}_{12} \\
\mathrm{~T}_{21} & \mathrm{~T}_{22}
\end{array}\right]\left(\begin{array}{l}
\mathrm{P}_{4} \\
\mathrm{~V}_{4}
\end{array}\right)
$$

Where $\mathrm{p}_{1}$ and $\mathrm{v}_{1}$ are the sound pressure and normal volume velocity, at the inlet and $\mathrm{p}_{4}$ and $\mathrm{v}_{4}$ are the sound pressure and normal volume velocity, at the outlet of the muffler.

$$
\begin{aligned}
& {\left[\begin{array}{ll}
\mathrm{T}_{11} & \mathrm{~T}_{12} \\
\mathrm{~T}_{21} & \mathrm{~T}_{22}
\end{array}\right]=\left[\begin{array}{ll}
\mathrm{A}_{11} & \mathrm{~A}_{12} \\
\mathrm{~A}_{21} & \mathrm{~A}_{22}
\end{array}\right]\left[\begin{array}{ll}
\mathrm{B}_{11} & \mathrm{~B}_{12} \\
\mathrm{~B}_{21} & \mathrm{~B}_{22}
\end{array}\right]\left[\begin{array}{ll}
\mathrm{C}_{11} & \mathrm{C}_{12} \\
\mathrm{C}_{21} & \mathrm{C}_{22}
\end{array}\right]} \\
& {\left[\begin{array}{ll}
\mathrm{T}_{11} & \mathrm{~T}_{12} \\
\mathrm{~T}_{21} & \mathrm{~T}_{22}
\end{array}\right]=\left[\begin{array}{cc}
\cos \left(\mathrm{kl}_{\mathrm{A}}\right) & \frac{\rho \operatorname{csin}\left(\mathrm{kl}_{\mathrm{A}}\right)}{\mathrm{S}_{\mathrm{A}}} \\
\frac{\mathrm{S}_{\mathrm{A}} \sin \left(\mathrm{kl}_{\mathrm{A}}\right)}{\rho \mathrm{c}} & \cos \left(\mathrm{kl}_{\mathrm{A}}\right)
\end{array}\right]\left[\begin{array}{cc}
\cos \left(\mathrm{kl}_{\mathrm{B}}\right) & \frac{\rho \sin \left(\mathrm{kl}_{\mathrm{B}}\right)}{\mathrm{S}_{\mathrm{B}}} \\
\frac{\mathrm{S}_{\mathrm{B}} \sin \left(\mathrm{kl}_{\mathrm{B}}\right)}{\rho \mathrm{c}} & \cos \left(\mathrm{kl}_{\mathrm{B}}\right)
\end{array}\right]\left[\begin{array}{cc}
\cos \left(\mathrm{kl}_{\mathrm{C}}\right) & \frac{\rho \operatorname{csin}\left(\mathrm{kl}_{\mathrm{C}}\right)}{\mathrm{S}_{\mathrm{C}}} \\
\frac{\mathrm{S}_{\mathrm{C}} \sin \left(\mathrm{kl}_{\mathrm{C}}\right)}{\rho \mathrm{c}} & \cos \left(\mathrm{kl}_{\mathrm{C}}\right)
\end{array}\right]}
\end{aligned}
$$


Where subscript 'A' indicates to inlet tube (A), 'B' to main chamber (B) and ' $C$ ' to outlet tube (C).

Transmission loss of this muffler can be calculated by following expression.

$$
T L=20 \log \left(\frac{1}{2}\left|\mathrm{~T}_{11}+\frac{\mathrm{T}_{12}}{\mathrm{Y}_{1}}+\mathrm{T}_{21} \mathrm{Y}_{3}+\mathrm{T}_{22}\right|\right)
$$

\subsection{Experimental Validation}

Sound analyzer consists of two assemblies namely input signal (Green Color) which refers to upstream and output signal (Red Color) which indicates to downstream with computer interfacing as shown in Fig.2. The differences of FFT of these two signals are analyzed in Matlab based sound spectrum software which is developed by authors Amit Kumar Gupta and Dr. Ashesh Tiwari. The difference of upstream and downstream sound pressure level is calculated as transmission loss. This circuit provides the sensitivity, frequency and range selection facility.

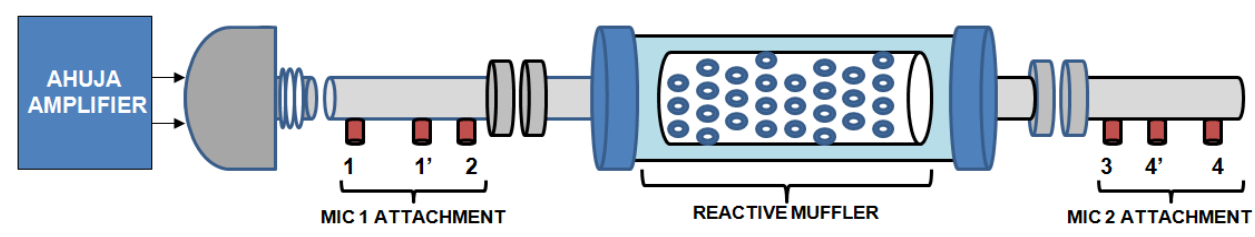

Fig.2. Schematic Layout of Test Rig

The experiment is performed for frequency range of 1 to $3000 \mathrm{~Hz}$. The readings are taken in two slots with two locations 1-1' and 4-4' which is shown in figure respectively to achieve desired frequency range. The locations 1-2-3-4 are used for measuring pressure in frequency range 10-400 Hz, while the locations 1'-2-3-4' are used for measuring pressure in frequency range of 400-3000 Hz.

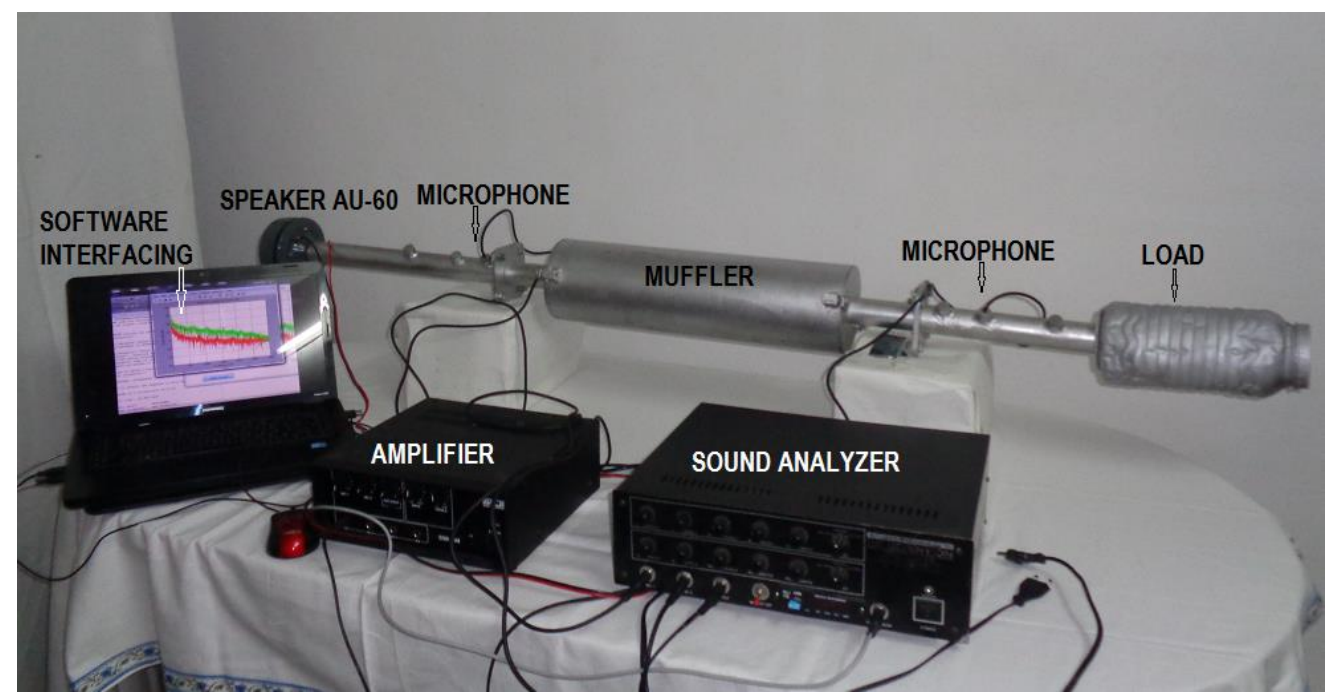

Fig.3. Experimental Test Set Up Measurement for Central Inlet and Outlet 
Two microphones are used for measurement, which are sufficient for measurement of transfer function between sound pressures measured at two locations. All other locations except locations where microphone are inserted are sealed with rubber cap to avoid sound leakage as shown in Fig. 3.

\subsection{Comparison with FEA Tool (Wave-1D)}

Wave 1-D is a 1-dimensional gas dynamics code which is based on finite volume method for simulating engine cycle performance. Tools using this one-dimensional approach accurately predict all engine breathing characteristics as shown in Fig. 6.
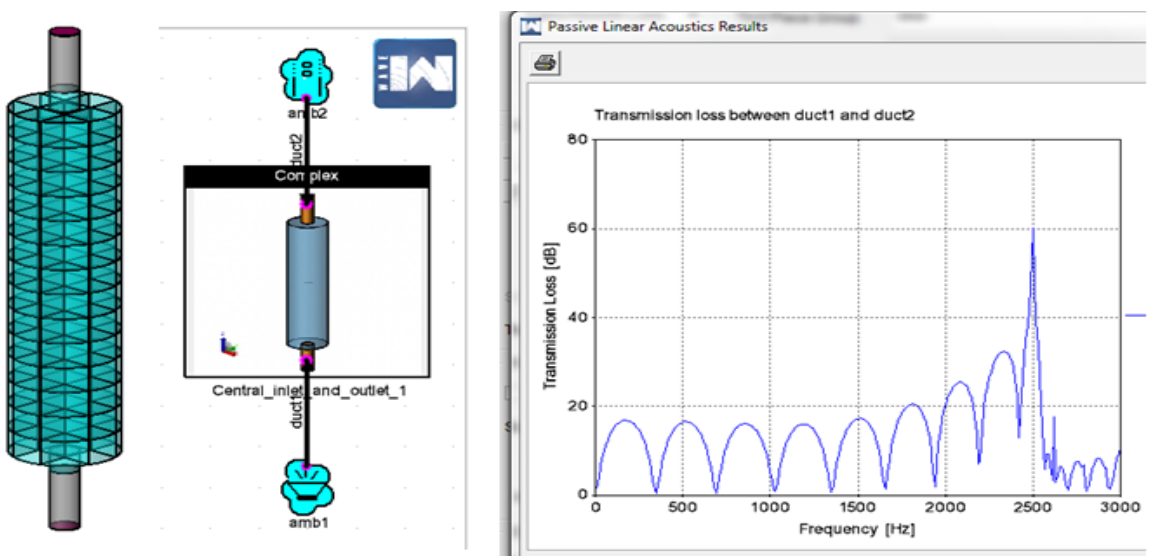

Fig.4. Wave 1-D GUI for Central Inlet and Central Outlet

\subsection{Comparison with FEA Tool (comsol)}

To evaluate the transmission loss performance of muffler comsol is used for single expansion chamber with central inlet and central outlet pipe. In this calculation, the mean flow of muffler is neglected shown in Fig. 5. The transmission loss is comparable with wave 1-D result.
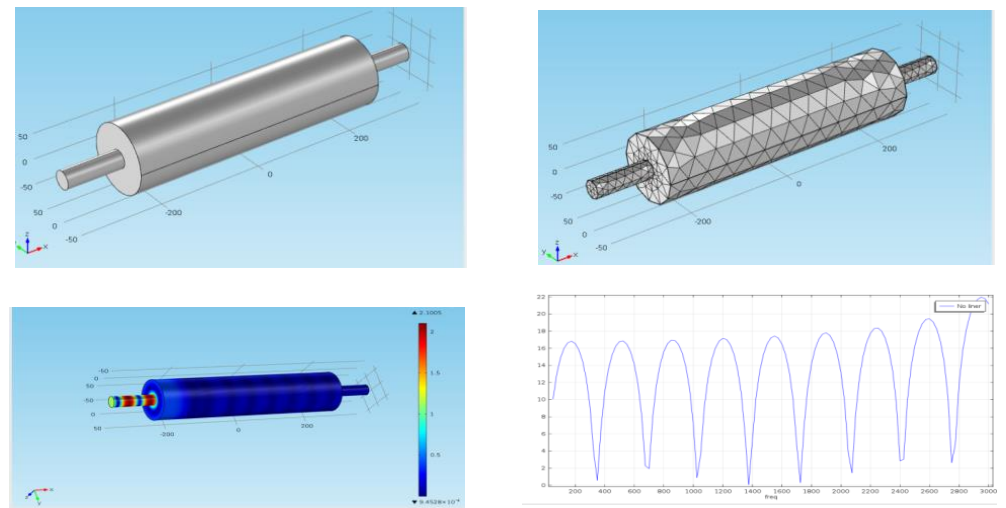

Fig.5. Comsol GUI for Central Inlet and Central Outlet

\subsection{Results comparison with Experimental and Wave 1-D}


Fig.6 Shows that the experimental result \& FEA results is matched. Small differences may be due to sound leakage from muffler [16].

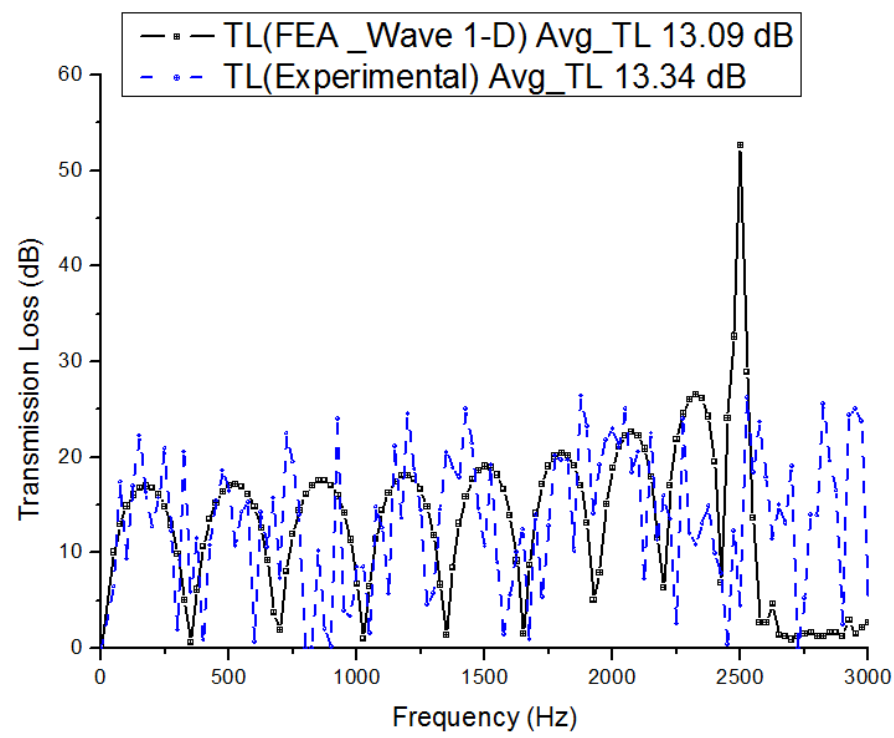

Fig.6. Results Comparison with Experimental and Wave 1-D for Central Inlet and Outlet

\subsection{Results comparison with Transfer Matrix Method, Comsol and Wave 1-D}

Fig.7 Shows that the experimental result and FEA results are matched with each other. Small differences may be due to sound leakage from muffler.

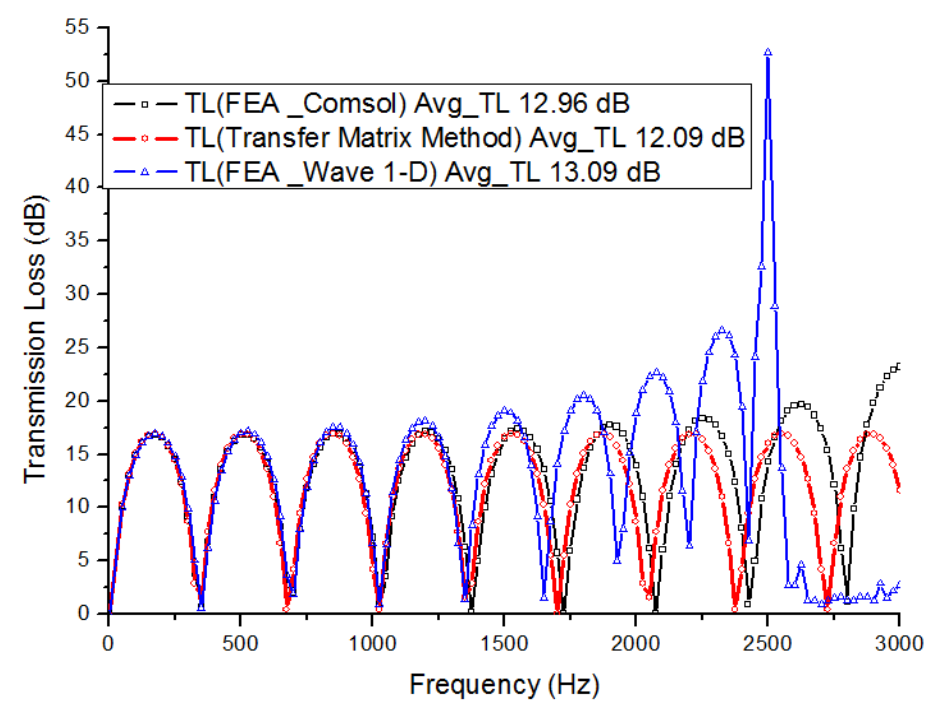

Fig.7. Results Comparison with TMM, Comsol and Wave 1-D for Central Inlet and Central Outlet 


\section{Offset inlet and Offset outlet muffler validation with FEA Tool}

\subsection{Effect on Transmission Loss for Central Inlet \& Outlet Moves Radial Linearly}

With reference to the Fig. 1 the length of expansion chamber is $500 \mathrm{~mm}$ and the diameter of expansion chamber is $130 \mathrm{~mm}$ and diameter of inlet tube as well as outlet tube is $35 \mathrm{~mm}$. The effect of TL has been observed by increasing the offset by 0.2 times of ' $r$ ' which is radius of expansion chamber of $65 \mathrm{~mm}$ diameter.

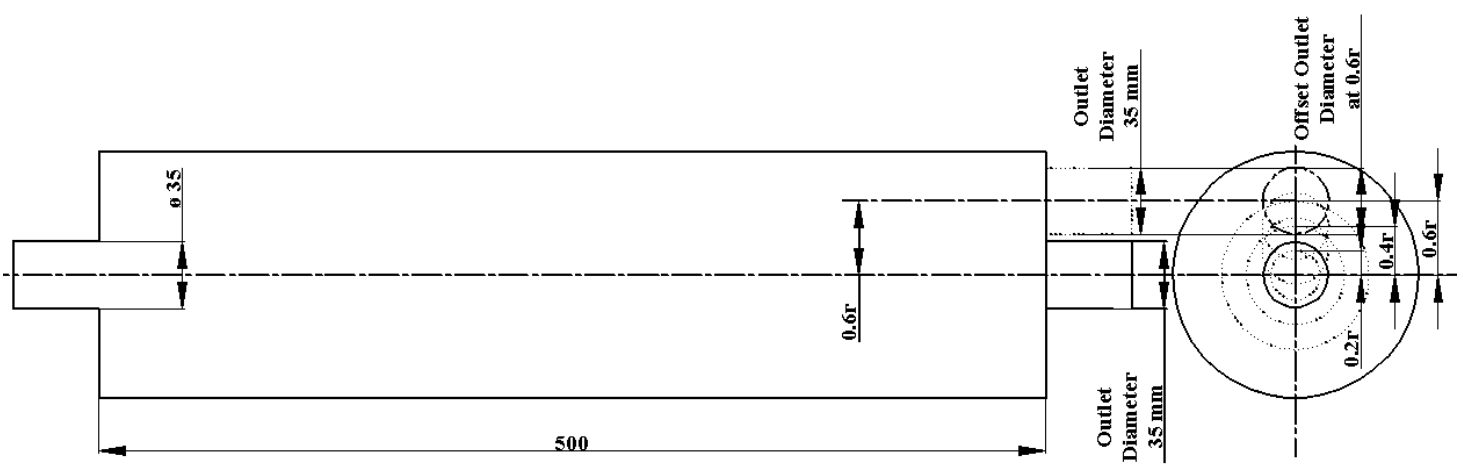

Fig.8. Radial Offset Outlet Pipe

In this case of expansion chamber, the dimensions of chambers are taken in such a way to observe wave propagation phenomenon. The length to diameter ratio was also so chosen so that one dimensional calculation becomes realistic for a sufficiently wide frequency range. The transmission loss has been chosen as suitable magnitude representative of the frequency response of a given muffler. It is defined in terms of logarithmic ratio between the acoustic power incident on the muffler and the acoustic power transmitted by the muffler. The cross section of the ducts upstream and downstream of the muffler is same. Here transmission loss reduces to the ratio between the amplitudes of the incident and the transmitted waves. The study was focused on the quality of the results obtained, taking into account the sensitivity of the mesh spacing so used.

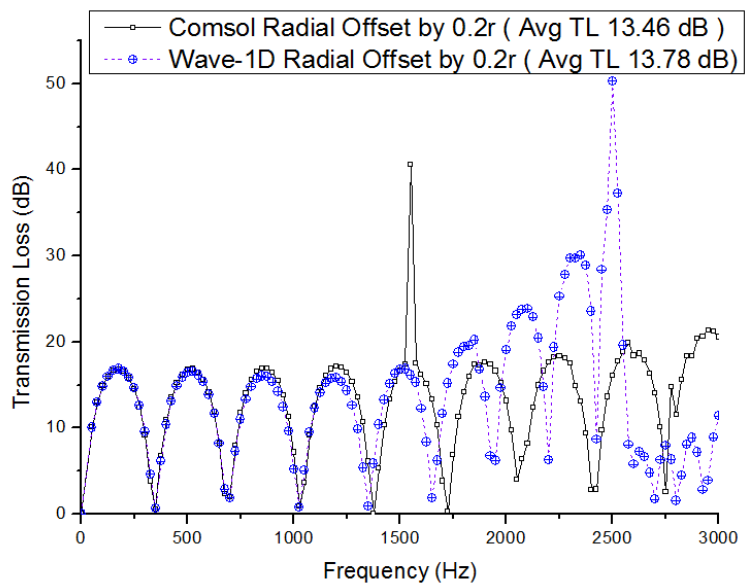

(a)

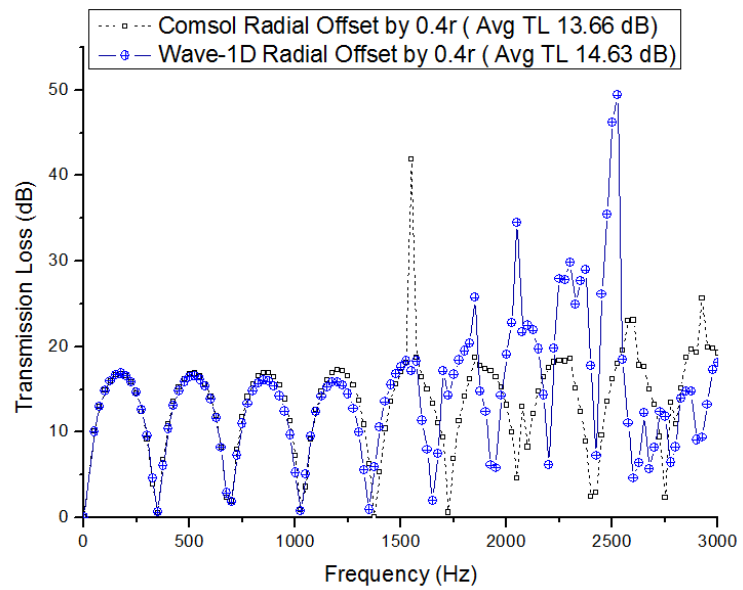

(b)

Fig.9. When outlet at (a) 0.2 r; (b) $0.4 r$; 


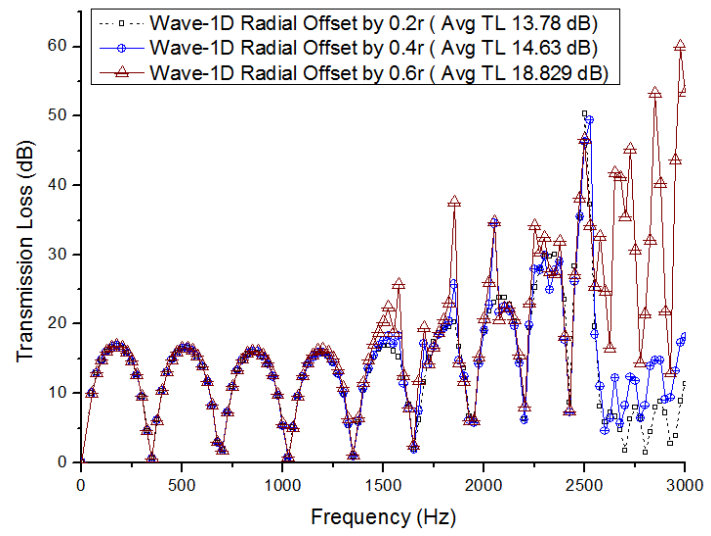

(a)

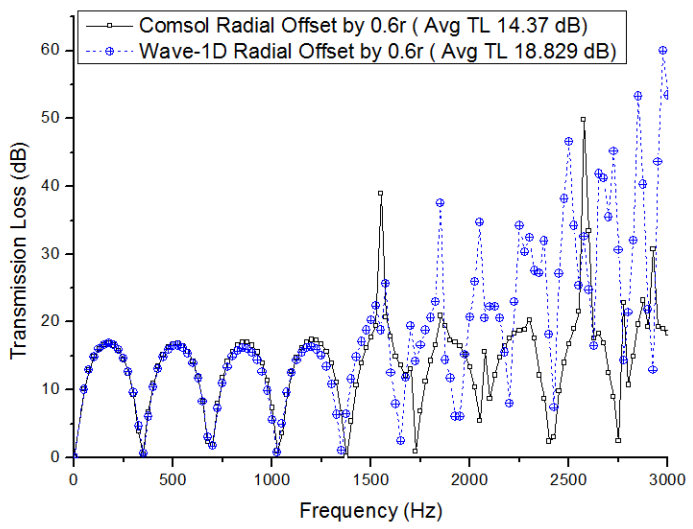

(b)

Fig.10. When Outlet at (a) 0.6 r; (b) Overall Comparison of Radial Offset

The curve represent that the transmission loss increases with increasing the radial linear offset distance of outlet. Small deviation is appeared due to the meshing parameter in both the FEA tools.

Table 1. Transmission Loss Measurement by Offsetting Outlet Radially

\begin{tabular}{ll}
\hline Offset of Outlet Pipe (by wave 1-D) & $\begin{array}{l}\text { Transmission Loss } \\
(\mathrm{dB})\end{array}$ \\
\hline At Central Position & 13.09 \\
Radial offset of $0.2 \mathrm{r}$ & 13.78 \\
Radial offset of $0.4 \mathrm{r}$ & 14.63 \\
Radial offset of $0.6 \mathrm{r}$ & 18.82 \\
\hline
\end{tabular}

From the above Table 1 it is clear that the transmission loss improved up to $5.73 \mathrm{~dB}$ by increasing the offset distance of outlet radially from central position to $0.6 \mathrm{r}$.

\subsection{Effect on Transmission Loss for Offset Inlet At $0.6 r \&$ Offset Outlet at $0.6 r$ and Outlet Rotates Radial}

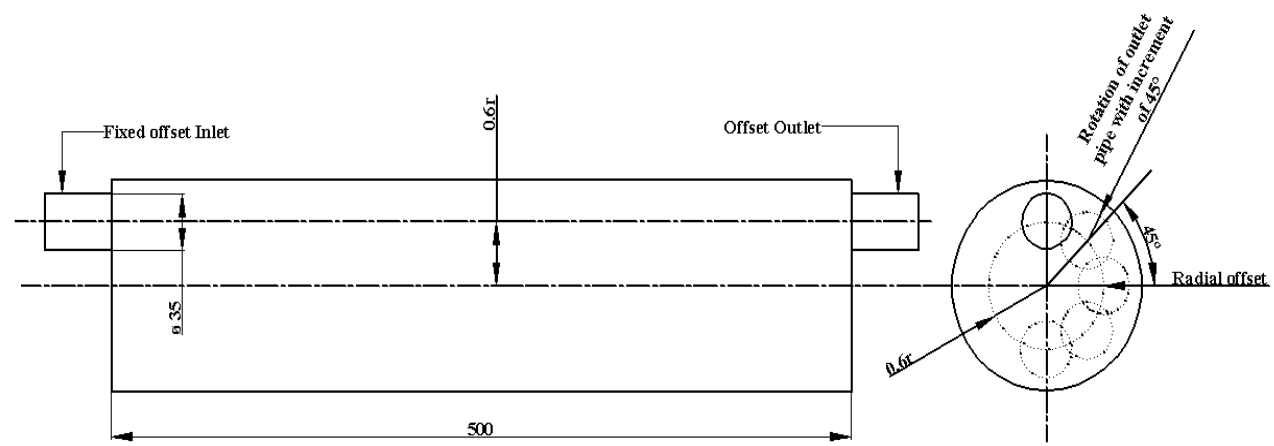

Fig.11. Rotational Offset of Outlet Pipe 


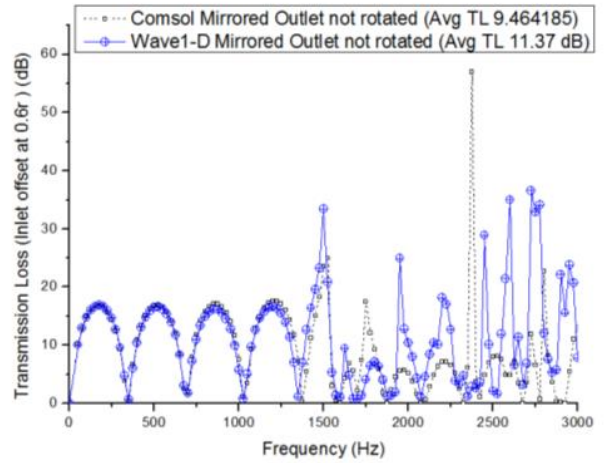

(a)

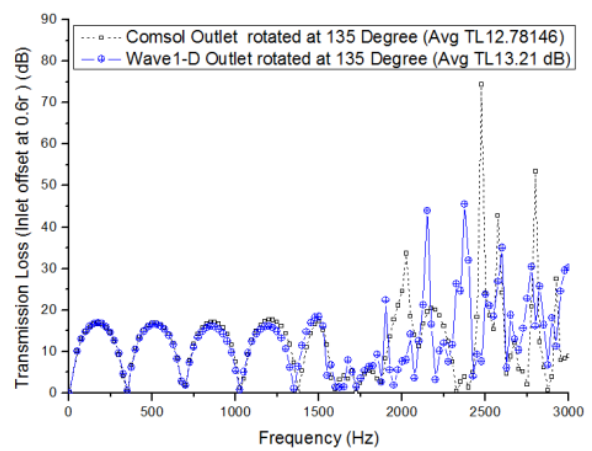

(c)

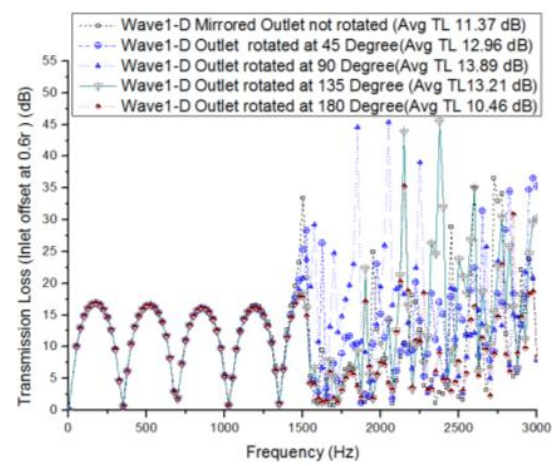

(e)

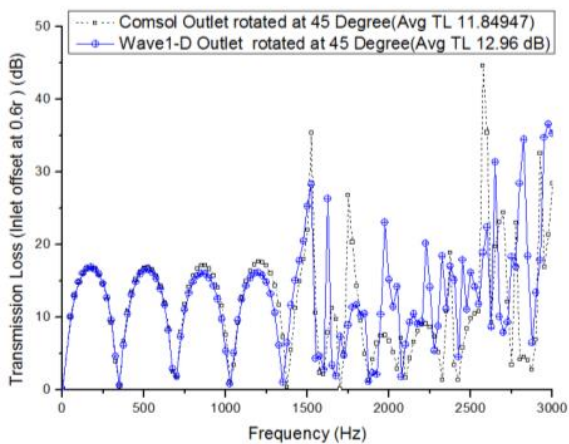

(b)

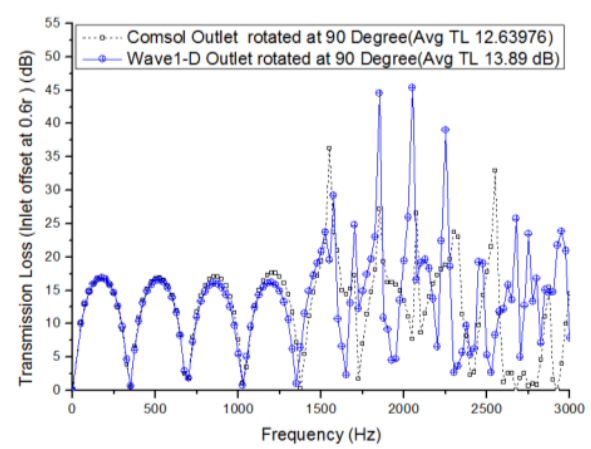

(d)

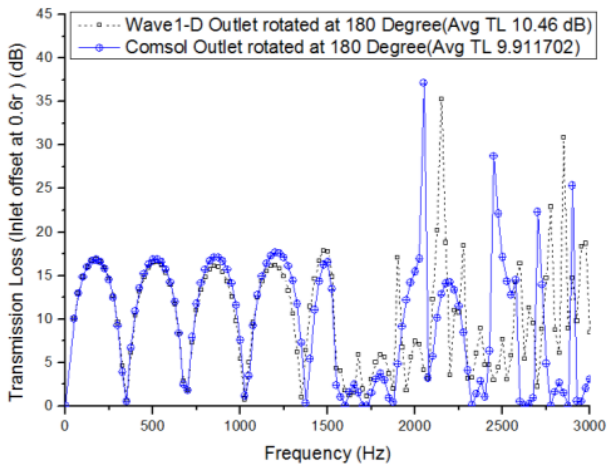

(f)

Fig.12. Finite Element Analysis Results of Rotating Offset Outlet Pipe

This spikes which are observed in FEA results may be due to singularities at the sharp corners which many times pollute the results adjacent to the singularities. But in acoustics sudden increase in transmission loss at a particular frequency may be neglected because transmission loss is a function of incident power to transmitted power. When incident power is constant and transmitted power approaches to zero transmission loss approaches to infinity which is not possible in physical system at a particular frequency and so results are considered without spikes. 
Table 2. Transmission Loss Measurement by Offsetting Outlet Radially

\begin{tabular}{ll}
\hline $\begin{array}{l}\text { Rotating outlet pipe by fixed inlet pipe both offset } \\
\text { by } 0.6 r \text { (by wave 1-D) }\end{array}$ & $\begin{array}{l}\text { Transmission Loss } \\
(\mathrm{dB})\end{array}$ \\
\hline Offset inlet and offset outlet with $0^{\circ}$ rotation & 11.37 \\
Offset inlet and offset outlet with $45^{\circ}$ rotation & 12.96 \\
Offset inlet and offset outlet with $90^{\circ}$ rotation & 13.89 \\
Offset inlet and offset outlet with $135^{\circ}$ rotation & 13.21 \\
Offset inlet and offset outlet with $180^{\circ}$ rotation & 10.46 \\
\hline
\end{tabular}

Study in five cases has been undertaken to observe transmission loss at each case which reveals that the maximum transmission loss is at $90^{\circ}$. From the above Table 2 it is clear that the transmission loss improved up to $2.52 \mathrm{~dB}$ by rotating outlet pipe by $90^{\circ}$ fixed inlet pipe both offset by $0.6 \mathrm{r}$.

\section{Conclusions}

The experimental results show good agreement with the numerical results. From this result it can be concluded that the developed experimental setup can measure the performance of Muffler's Transmission loss. The small deviation in the result of experiment from the numerical results may be due to sound leakage, low surface finish of impedance tube, and problems in generating white noise from the FFT sometimes it is not accurate. Now any shape of muffler can be modeled to predict the transmission loss (TL). In recent scenario so many complicated geometry of muffler where the practical analysis proves too expensive and complicated. So the FEA tool can be the best approach to achieve the expected outcomes regarding the transmission loss of Muffler. Attenuation curves represent among three observations in case of radial offset of the outlet duct at distance $0.2 \mathrm{r}, 0.4 \mathrm{r}$ and $0.6 \mathrm{r}$ by keeping inlet duct at central location. It clearly shows that the high transmission loss can be achieved at the outlet position of $0.6 \mathrm{r} \mathrm{mm}$ offset from the central location (shown in Fig. 8). From the above Table 1 it is clear that the transmission loss improved up to $5.73 \mathrm{~dB}$ by increasing the offset distance of outlet radially from central position to 0.6r. Further higher attenuation can also be achieved in case of fixed the distance of offset inlet and outlet at $0.6 \mathrm{r}$ by rotating the offset outlet by $0^{\circ}, 45^{\circ}, 90^{\circ}, 135^{\circ}$ and $180^{\circ}$. Study has been undertaken in five cases it is observed that transmission loss at each case which reveals that the maximum transmission loss is at $90^{\circ}$. It represents higher attenuation can achieved in case of $90^{\circ}$ rotation of offset outlet as shown in Fig. 12 (c). This method can be applied for any silencer configuration and also it offers fast initial prototype solutions for silencer designers. Also calculation of Transmission loss by experimental method and FEA tool show good agreement.

\section{Acknowledgements}

Thanks to support from everyone including parents, teachers, family and friends. Especially I would like to dedicate my acknowledgement of gratitude towards the IET-DAVV to provide the research facility.

\section{References}

[1] M. L. Munjal, "Recent Advances in Muffler Acoustics", International Journal of Acoustics and Vibration, Vol. 18, No. 2, pp. 71-85,2013.

[2] A. K. Gupta, and A.Tiwari, "Measurement of Sound Transmission Loss on Straight and Zigzag Perforated Concentric Tube Muffler with Constant Porosity", International Journal on Emerging Technologies Vol.6, Issue 2, pp 35-40, 2015. 
[3] R. Barbieri and N.Barbieri, "Finite element acoustic simulation based shape optimization of a muffler", applied acoustics, Volume 67, Issue 4, pp 346-357, 2006.

[4] L.J.Yeh, "Computer-aided optimal design of a single-chamber muffler with side inlet/outlet under space constraints", Journal of Marine Science and Technology, Vol. 11, Issue 4, pp. 189-196, 2003.

[5] A.K. Gupta and A. Tiwari "Comparison of Existing Experimental Results with Different Types of Simulation Software for Transmission Loss Estimation of Muffler", March 2015, Volume 2, Issue 1,Trends in Machine Design, pp 17-20, 2015.

[6] Min GUO, Chunhua JIA I.J., "Neural Network Recognizes Fruit Fly's Wing Vibration Sound Based on Hilbert-Huang Transform", I.J. Engineering and Manufacturing, Vol. 1, Issue 6, pp. 25-30, 2011.

[7] M.L.Munjal, Acoustics of Ducts and Muffler, Wiley, New York, 1987.

[8] A. Selamet, and Z.L. Ji, "Acoustic attenuation performance of circular expansion chambers with extended inlet/outlet", Journal of Sound and Vibration, 223, pp197-212, 1999.

[9] R. Mohamed SabryAllam et. al., "Modelling and analysis of single expansion chamber using response surface methodology" international journal of mechanical and materials engineering vol.2 issue 1, 2012.

[10] Z. Tao and A.F. Seybert, "A review of current techniques for measuring muffler transmission loss" SAE 2003.

[11] A.K.M. Muhiuddin, A. Rahman and Y.B. Gazali, "Simulation and experimental investigation of muffler performance" international journal of mechanical and materials engineering,Vol2,2007.

[12] C.Y.R. Cheng, and A.F. Seybert, "A multi domain boundary element solution for silencer and muffler performance prediction", J. Sound and Vibration, pp 119-129, 1991.

[13] S.N.Y Gerges et.al., "Muffler Modeling by Transfer Matrix Method and Experimental Verification", J. Braz. Soc. Mech. Sci.\& Eng., vol. 27, no.2, pp.132-140, 2005.

[14] A.K. Gupta and A. Tiwari, "Modeling For Transmission Loss Prediction Of Different Shapes Of Acoustic Muffler With An Experimental Analysis", Journal Of Experimental \& Applied Mechanics, Vol 6, No 1, 2015.

[15] Bhattu A.P., Sahasrabudhe A.D. "Acoustic Performance of Reactive Central Inlet and Side Outlet Muffler by Analytical Approach", International Journal of Engineering and Innovative Technology, Volume 2, Issue 1, pp 44-49, 2012.

[16] A.K. Gupta and A. Tiwari, "Transfer Matrix Method for Noise Attenuation on Single Expansion Chamber Muffler having Central Inlet and Central Outlet with Experimental Techniques and FEA Validation", International Journal of Theoretical \& Applied Sciences, Vol. 7, Issue 2, pp. 14-20, 2015.

\section{Authors' Profiles}

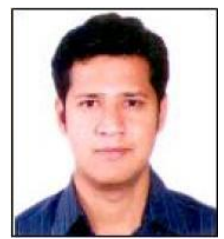

Mr. Amit Kumar Gupta obtained his B.E. degree in Mechanical Engineering from IETDAVV Indore (M.P.), India. He received his M.E. in "Computer Integrated Manufacturing" from S.G.S.I.TS., Indore (MP) India. Currently He is pursuing Ph.D. in the area of Muffler Noise Reduction. Presently he is working as Assistant Professor in Mechanical Engineering Department, Institute of Engineering \& Technology, Devi Ahilya University, Indore, India. His areas of interest are machine design, CAD modelling tools, finite element analysis tool and acoustics. E-mail address: gupta.ak4@gmail.com.

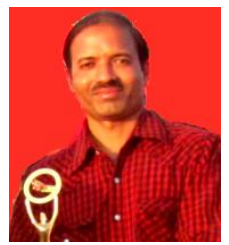

Dr. Ashesh Tiwari is working as Professor \& Head of the Mechanical Engineering Department, Institute of Engineering \& Technology - Devi Ahilya University, Indore (MP). He has published more the 50 research paper and guided 6 Ph.D. scholars and currently 6 $\mathrm{Ph} . \mathrm{D}$. scholars are registered under his guidance. His area of interest, Tribology, Vibration \& Noise Control, Machine Design. E-mail address: asheshtiwari1@ @ediffmail.com. 